\title{
Analysis of the Y2K problem from the viewpoint of risk communication
}

\author{
M. Taniyama \& R. Sasaki \\ Tokyo Denki University, Japan
}

\begin{abstract}
Various risk factors have been increasing as the result of the increasing ubiquity of the Internet. In order to share recognition concerning the risk among participants such as the public, risk communication is necessary. To develop effective risk communication, it is important to examine examples from the past and to analyze the problems and their countermeasures. In this paper, we define risk communication, and then describe the $\mathrm{Y} 2 \mathrm{~K}$ problem as an example of risk communication. Through the investigation of newspapers and Web articles in both Japan and the United States, we describe the countermeasures taken with regard to the $\mathrm{Y} 2 \mathrm{~K}$ problem by the public, the government, mass media, and experts. These results are used to suggest countermeasures for risk communication regarding the Year 2038 problem, which is similar to the Y2K problem and for the risk against the information infrastructure, which may occur in the future.
\end{abstract}

Keywords: risk, risk communication, risk management, Y2K problem, Year 2038 problem.

\section{Introduction}

Various risks are related to the increasing ubiquity of the Internet. It is important to recognize and communicate these risks to those involved, including the general public. A method of determining appropriate risk communications that can be used to analyze future problems and form countermeasures is the examination of past examples.

In the present paper, we examine the $\mathrm{Y} 2 \mathrm{~K}$ problem because this problem was anticipated early on, discussed extensively, and had a known cause. 
We first describe the Y2K problem, and then explain risk communication and its implementation. In addition, we describe the behaviors of the general public, government, mass media, and experts in countering the $\mathrm{Y} 2 \mathrm{~K}$ problem by investigating newspapers and Web articles. These results are used to suggest countermeasures for not only risk communication of the Year 2038 problem, which is similar to the $\mathrm{Y} 2 \mathrm{~K}$ problem, but also the risk against the information infrastructure, which may occur in the future.

\section{The Y2K problem}

Early computers processed the year by the last two digits only, omitting the initial "19" [1]. As a result, upon reaching the year 2000, these computers read the year as 1900. It was thought that this would cause a great number of problems unless these two-digit years were replaced by four-digit years.

Three reasons why two-digit-years were used are described below:

(1) Keeping used memory capacity small was necessary, because from 1960 to 1980 , when these computers were made, memory and hard disks were very expensive.

(2) Using fewer characters decreases the possibility of typing error.

(3) Sidestepping compatibility issues in computer systems was, however, the biggest reason.

According to TIME magazine in the U.S., the Y2K problem was made public in 1979 by the journal "Interface Age" (Bemer [2]). Although the Y2K problem was recognized in the early stage and on a technical level, computer companies were able to handle the four-digit-years, as time advanced, the two-digit-year dates were continually used.

Problems envisioned by $\mathrm{Y} 2 \mathrm{~K}$ included the incorrect setting of dates and miscalculations of years and leap years. These problems would have occurred with certainty if countermeasures had not been taken. In the early stages of risk management, the $\mathrm{Y} 2 \mathrm{~K}$ problem was identified in the mainframes of financial institutions and countermeasures were taken.

However, in the middle of 1997, when it was realized that embedded computer chips containing date data might cause the $\mathrm{Y} 2 \mathrm{~K}$ problem, the scope of potential problems increased significantly, and the $\mathrm{Y} 2 \mathrm{~K}$ problem was then perceived as being more serious. In addition, because embedded computer chips were used in countless applications, some people thought it would be almost impossible to manage this problem before the year 2000. Serious problems that would have been caused by misrecognition of the date included failures of electric power supply and financial facilities. In addition, other outcomes included accidents, such as plane crashes and accidental missile launches.

In the present paper, we consider the Y2K problem simply as a problem of setting and miscalculating dates. Hence, it was necessary for various countermeasures to be adopted. Although Y2K may have caused plane crashes and accidental missile launches, these risks were not unique to the Y2K problem. Therefore, people should not have overreacted to these problems. 


\section{Overview of risk and risk communication}

There are a number of definitions of risk. Unlike a hazard, a risk has a probability associated with it. In one definition, risk is defined as "the probability of the occurrence of an undesired event" [3]. In the field of engineering, the definition of risk is given as the probability of an event occurring times the impact associated with the event.

The National Research Council (NRC) defines risk communication as "an interactive process of exchange of information and opinion among individuals, groups, and institutions" [4].

A number of studies have investigated risk communication for systems such as nuclear plants and chemical plants, which have an impact on human health when a disaster strikes. Few research studies, however, have examined risk communication in information systems.

Although various methods have been used to investigate risk communication, we classify these into three methods, as follows.

(1) Research on the model of the concept of risk communication. Within this method, the "communication model for risk information sharing" has been suggested [5].

(2) Research on the demonstration of risk communication. The method of observing the process of risk communication and analyzing newspaper articles has been conducted in the field of demonstration [6].

(3) Research on tools supporting risk communication The "Multiplex Risk Communicator," which supports searching the best combination of countermeasures and obtaining a consensus of the participants, has been suggested as a tool supporting risk communication [7].

In the present paper, we investigate the $\mathrm{Y} 2 \mathrm{~K}$ problem using method (2). In other words, we investigate how information on $\mathrm{Y} 2 \mathrm{~K}$ was exchanged or shared by analyzing newspapers and Web articles. This is the first such study on the Y2K problem.

\section{Investigation and analysis of the $\mathrm{Y} 2 \mathrm{~K}$ problem}

\subsection{Model of risk communication}

The flow of information in the Y2K problem is shown in Fig. 1. Here, we mainly investigate and analyze the information on risk that is provided to the public by the mass media, the government, and experts and the information on risk that is provided to the critical infrastructure by the government (indicated by thick lines in Fig. 1).

\subsection{Method of investigation}

We referred to the following media to investigate articles on the Y2K problem: (1) Japanese national newspapers: The Asahi Shimbun, The Yomiuri Shimbun, The Nihon Keizai Shimbun, and The Mainichi Shimbun. 


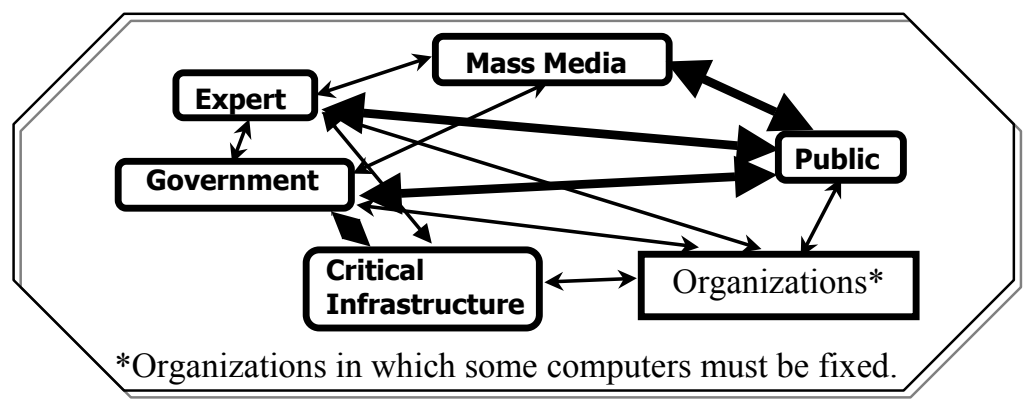

Figure 1: $\quad$ Flow of information in the Y2K.

(2) U.S. newspapers: USA Today, The New York Times, The Wall Street Journal, and The Washington Post.

(3) Web sites: government, press, and several sites that deal mainly with the Y2K problem.

Articles in the Japanese national newspapers were researched at the Newspaper Library, which is located in Yokohama, Japan, using an online database called "G-Search" [8]. Articles in the U.S. newspapers were researched at the National Diet Library using an online database called "ProQuest Newsstand" [9]. Web sites that were no longer active at the time of research were accessed using the Internet Archive [10].

\subsection{How the public dealt with the Y2K problem}

Various communities were established both in the U.S. and Japan to deal with the Y2K problem. These communities were small volunteer groups that informed the public and the government of the Y2K problem; the existence of these groups indicates that some of the public was interested in the risk. These communities then undertook risk communication with the government, companies, and the public.

Here, we chose the "Sedona Task Force" and the "Kauai Community Self Reliance Cooperative" from the U.S. communities and the "Y2K Shimin Net" and the "Y2K WASH Campaign" from the Japanese communities. Table 1 shows the date when these communities were established. As shown in Table 1, the U.S. communities were interested in the risks associated with the Y2K problem earlier and were established approximately 10 months earlier than the Japanese communities.

Table 1: $\quad$ Dates of community establishment.

\begin{tabular}{|l||l|l|}
\hline & Community & Date \\
\hline \hline \multirow{2}{*}{ Japan } & Y2K WASH Campaign & $1999 / 07 / 04$ \\
\cline { 2 - 3 } & Y2K Shimin Net & $1999 / 07 / 31$ \\
\hline \multirow{2}{*}{ U.S. } & Sedona Task Force & $1998 / 09$ \\
\cline { 2 - 3 } & Kauai Community Self Reliance Cooperative & $1998 / 10$ \\
\hline
\end{tabular}


Table 2: $\quad$ Recommended amounts of water and food supplies.

\begin{tabular}{|l||l|l|}
\hline \multirow{2}{*}{ Government } & Japan (Prime Minister of Japan and his Cabinet) & A few days \\
\cline { 2 - 3 } & $\begin{array}{l}\text { U.S. (Federal Emergency Management Agency } \\
\text { (FEMA)) }\end{array}$ & Three days \\
\hline Communities & Y2K Shimin Net Tokyo & One month \\
\hline Other & American Red Cross & Several days \\
\hline
\end{tabular}

These communities held workshops in order to inform the public about how they should prepare for the Y2K problem. Similarly, the government informed the public about preparing for the $\mathrm{Y} 2 \mathrm{~K}$ problem. The information on preparedness included the amounts of water and provisions that the public should set aside. However, information provided by the communities and the government differed significantly, indicating that communities did not always agree with the government's directions (Table 2).

The public prepared water and food supplies based on government and community recommendations. Polls were conducted in both Japan and the U.S. at almost the same time (mid-November, 1999), and the results were compared between the two countries. The poll in Japan was conducted by The Yomiuri Shimbun and surveyed approximately 1,900 people, while the poll in the U.S. was conducted by the Gallup Company and surveyed approximately 1,000 people.

The polls indicated that $23 \%$ of Japanese citizens and $40 \%$ of American citizens set aside supplies of water and food. This result indicates a difference in awareness of the risk between Japanese and American citizens.

However, consequently, Japanese and American citizens did not set aside excessive amounts of supplies, but rather prepared calmly, although there were some precautions against the Y2K problem [1]. Upon entering the year 2000, there was no chaos among the public, and the public dealt with the $\mathrm{Y} 2 \mathrm{~K}$ problem calmly throughout.

As noted above, the public dealt with the Y2K problem calmly, but Japanese and American citizens viewed the risk of Y2K differently and tackled it differently. In addition, the date when the communities were established differed.

In summary, the factors that influenced the effects of communication and risk communication were integrated into the sender, receiver, contents of the message, and the media [11]. We show the types of information that senders, such as the government, mass media, and experts, provided to the public and analyze how this information influenced the citizens of Japan and the U.S. in Sections 4.4 to 4.6 .

\subsection{How governments dealt with the Y2K problem}

\subsubsection{Countermeasures taken within the critical infrastructures [1]}

It was necessary to take countermeasures within the critical infrastructure against the Y2K problem, because a crash of the critical infrastructure could cause a great impact to the public, such as a power outage: 
(1) The Japanese government established "Y2K Action Plan" on September 11, 1998 and conducted the countermeasures in the plan. The parts of the countermeasures taken within the critical infrastructures are written below.

(a) Government agencies encouraged each critical infrastructure to figure out the $\mathrm{Y} 2 \mathrm{~K}$ problem, conduct the simulated tests and correct the programme if something wrong occurred, and establish a crisis management plan.

(b) Government agencies asked each critical infrastructure to report its results of the simulated tests four times a year.

These requirements made the critical infrastructures tackle the Y2K problem. Almost all of the simulated tests were completed by September 1999, as shown in Table 3. Moreover, the percentage of computer programme correction is the same as the percentage of completed simulated tests in September 1999.

Table 3: $\quad$ Percentage of simulated tests that were completed [1].

\begin{tabular}{|c|c|r|r|r|}
\hline Critical Infrastructure & Field & 1999.03 & 1999.06 & 1999.09 \\
\hline \multirow{3}{*}{ Monetary } & Bank & $72.0 \%$ & Unknown & $100.0 \%$ \\
\cline { 2 - 5 } & Insurance & $72.0 \%$ & Unknown & $99.0 \%$ \\
\cline { 2 - 5 } & Securities & $73.0 \%$ & Unknown & $99.0 \%$ \\
\hline \multirow{3}{*}{ Energy } & Electricity & $85.0 \%$ & $98.8 \%$ & $99.5 \%$ \\
\cline { 2 - 5 } & Gas & $83.0 \%$ & $98.9 \%$ & $100.0 \%$ \\
\cline { 2 - 5 } & Oil & $73.0 \%$ & $91.0 \%$ & $98.0 \%$ \\
\hline \multirow{2}{*}{$\begin{array}{c}\text { Information- } \\
\text { Communication }\end{array}$} & $\begin{array}{c}\text { Telecommunicati } \\
\text { on }\end{array}$ & $69.0 \%$ & $99.7 \%$ & $100.0 \%$ \\
\cline { 2 - 5 } & Broadcast & $53.0 \%$ & $80.0 \%$ & $98.0 \%$ \\
\hline \multirow{2}{*}{ Transportation } & Aviation & $79.0 \%$ & $97.0 \%$ & $100.0 \%$ \\
\cline { 2 - 5 } & Railroad & $49.0 \%$ & $98.0 \%$ & $100.0 \%$ \\
\hline
\end{tabular}

(2) The Japanese government took countermeasures against embedded computer chips, which have a significant effect on the critical infrastructures. The Japanese government investigated the embedded computer chips and confirmed that the chips controlling the supply of electricity and gas did not contain date information. Moreover, if a timer was used, it was more difficult to ignore errors, and computer programming would become more difficult. Therefore, the government concluded the embedded computer chips for electricity and gas were not controlled by the date. In addition, the government directed various organizations to help other organizations that might have problems.

Due to these directions made by the Japanese government, problems that would have had a great impact on the public did not occur. Although small problems did occur, recovery was completed immediately.

Considering that problems that have a great impact on the public did not occur in the U.S., it is thought that the U.S. government also took the appropriate countermeasures within the critical infrastructures. 


\subsubsection{Countermeasures taken within the public}

The Japanese government conducted the following countermeasures to the public [1].

(1) The "Preparedness on the Y2K problem for the end of the year and the New Year" initiative was announced on October 29, 1999. This initiative stated that the public should prepare a few days' worth of supplies, such as those that are commonly prepared in the event of an earthquake or a flood, while the government announced that no disruption would occur as a result of the Y2K problem.

(2) After the Japanese government knew that the critical infrastructures completed the simulated tests and the needed corrections of the programme, it made the following announcement in "The Greeting of the Prime Minister" on October 26, 1999: "We consider that no disruptions to infrastructure will severely influence our daily lives as a result of the Y2K problem." It is likely that this announcement calmed the public's anxiety about the Y2K problem.

The U.S. government set up the following countermeasures, which were similar to those of the Japanese government:

(1) The President's Council on Year 2000 Conversion introduced 1-888USA-4-Y2K, a free $\mathrm{Y} 2 \mathrm{~K}$ information line providing consumers with information about the Year 2000 computer problem. 1-888-USA-4-Y2K offered information in common areas of concern, including power, telephones, banking, government programs, and household products.

(2) After the U.S. government knew that the critical infrastructures completed the countermeasures, President Clinton announced that $99.9 \%$ of the government's mission-critical computer systems were Y2K-compliant [12]. He then stated, "Today, the facts are clear: we have done our job, we have met the deadline, and we have done it well below cost projections."

As noted above, both the Japanese and the U.S. governments offered direction on Y2K preparedness for the public. Moreover, they made announcements to calm the public on the basis of sufficient investigation and countermeasures. These countermeasures helped to ensure that there was no panic among the public. Therefore, it can be considered that the countermeasures were appropriate.

\subsection{Mass media coverage of the Y2K problem}

Although there were numerous types of mass media, including newspapers, magazines, books, and television, that addressed the Y2K problem, we restricted our investigation and analysis to articles in Japanese and U.S. newspapers.

\subsubsection{Variation in the number of articles in newspapers}

Circulation and penetration rate of U.S. and Japanese newspapers, which were investigated in this paper, are shown in Table 4 and Table 5. Circulation and penetration rate of Japanese newspapers were high. Moreover, the sum of the penetration rates of these four Japanese newspapers is about $48 \%$, showing that 
these Japanese newspapers are a large information source for the public. Therefore, we decided to investigate these newspapers.

Circulation and penetration rate of U.S. newspapers, however, are low compared to Japanese newspapers, most likely due to the variety of newspapers in the U.S. Although circulation and penetration rate of U.S. newspapers are low, these newspapers are world famous and make a big impact on the public. Therefore, we decided to investigate these newspapers.

Table 4: $\quad$ Circulation and penetration rate of Japanese newspapers [13].

\begin{tabular}{|c|r|r|r|}
\hline & Circulation* & Penetration rate\# & Rank \\
\hline Yomiuri & $9,972,865$ & $19.51 \%$ & 1 \\
\hline Asahi & $8,039,088$ & $15.73 \%$ & 2 \\
\hline Mainichi & $3,945,421$ & $7.72 \%$ & 3 \\
\hline Nihon Keizai & $2,824,118$ & $5.52 \%$ & 4 \\
\hline
\end{tabular}

*Average circulation of morning edition per day

$\#$ Penetration rate $=\{$ Circulation/Number of Households $(51,102,005) * 100\}$

Table 5: $\quad$ Circulation and penetration rate of U.S. newspapers [14].

\begin{tabular}{|c|r|r|r|}
\hline & Circulation* & Penetration rate\# & Rank \\
\hline USA Today & $1,255,099$ & $1.10 \%$ & 1 \\
\hline Wall Street Journal & $1,012,750$ & $0.89 \%$ & 2 \\
\hline New York Times & 952,208 & $0.83 \%$ & 3 \\
\hline Washington Post & 330,586 & $0.29 \%$ & 8 \\
\hline
\end{tabular}

*Average circulation of weekday newspaper per day \#Penetration rate $=\{$ Circulation/Number of Households $(114,384,000$ [15])* $100\}$

The results of the investigation of the number of articles on Y2K in Japanese and U.S. newspapers are reported in Figures 2 and 3. The search for the number of articles in U.S. newspapers was conducted using the online database, "ProQuest Newsstand," using the keyword "Y2K." The search for the number of articles in Japanese newspapers was conducted using "G-Search," another online database. The morning, evening, local, and Tokyo editions were included in the search of Japanese newspapers.

Figures 2 and 3 indicate that Japanese newspapers began to cover the Y2K problem in 1996, and U.S. newspapers began to cover the Y2K problem in 1997. These early and numerous reports informed many members of the public about the risk. As a result, it was thought that some of the public were probably interested in the Y2K problem and thereafter established the communities. These communities then conducted risk communication with the government, businesses, and the public. Therefore, we suggest that the number of articles on Y2K and the timing for covering the problem in Japanese and U.S. newspapers were appropriate. 


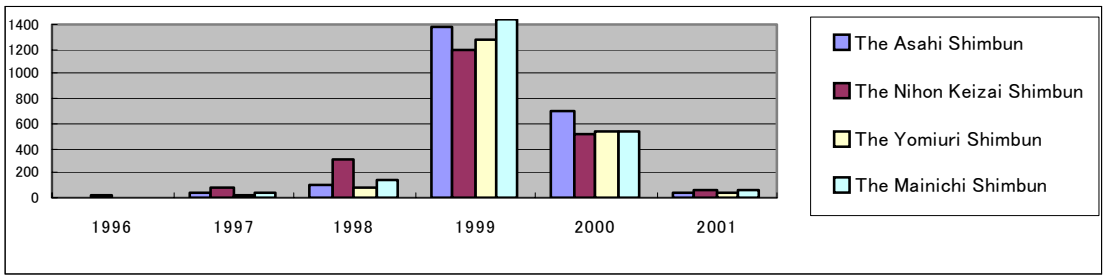

Figure 2: Variation in the number of articles in Japanese newspapers per year.

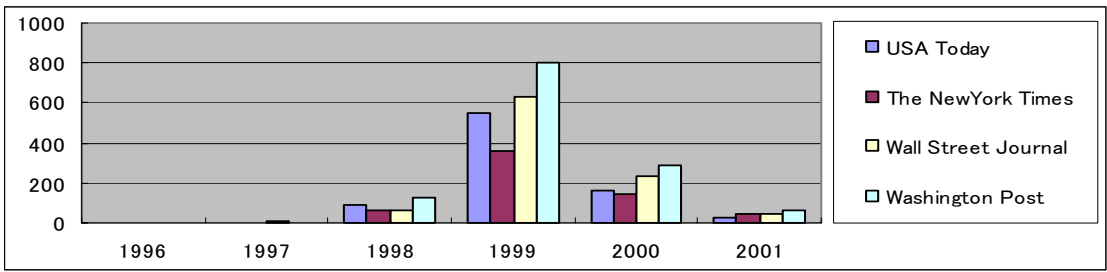

Figure 3: Variation in the number of articles in U.S. newspapers per year.

\subsubsection{Trends of the articles in newspapers}

The trends of articles in Japanese and U.S. newspapers differed. Fukumoto and Meares [16] investigated articles in The Yomiuri Shimbun and The New York Times and used four risk perception dimensions to find differences in the coverage between the two newspapers.

Every $10^{\text {th }}$ article was sampled randomly for this study. A total of 50 The Yomiuri Shimbun articles and 52 The New York Times articles were selected and classified. The coding unit for this analysis is a sentence. If the article was about another subject and only mentioned the $\mathrm{Y} 2 \mathrm{~K}$ problem in passing, the next relevant article was chosen. Articles that appeared after December 31, 1999 were not included.

Tables 6 and 7 are derived from Table 1 in [16]. Articles are classified using risk perception dimension, control, and impact. In this section, we describe the trends of the articles in Japanese and U.S. newspapers using Tables 6 and 7.

Table 6 indicates that The Yomiuri Shimbun had more articles reporting "Can Control" and "Under Control." In contrast, The New York Times had few articles describing situations as being under control.

This result is interpreted as a difference in the trends of articles in Japanese and U.S. newspapers. Moreover, this result can be taken as evidence that these differences influenced the public perception of the risk, because media coverage plays a large role in describing risk to the public. Additionally, this can be taken as evidence that mass media coverage may have changed in response to public concerns.

Table 7 indicates that there are a few articles describing the Y2K problem's impact as "Severe," meaning threatening to human life and "Inconvenient," meaning minor anticipated impact. Japanese national newspapers and U.S. 
famous newspapers, which are highly trusted by the public, need to inform correctly and not sensationalize. Thus, the trend of articles in Japanese and U.S. newspapers was appropriate.

However, some sensational articles appeared in Japanese weekly magazines. For example, an article was written on the base of 20 experts' opinions in "Shukan Gendai" and was published on December 25, 1999. This article describes that the power supply would be cut off, the trains would stop, and the stoplights would not work, causing many people to run to the supermarket to purchase food in case of a major Y $2 \mathrm{~K}$ problem.

This article was published only to attract the public attention by way of its fears, because this article appeared after the Japanese government made the safety announcement and the probability of this story actually happening was extremely low. Many Japanese, however, did not panic, because they did not believe the articles in the weekly magazine, which also has some gossip stories.

Table 6: $\quad$ Control over the Y2K problem.

\begin{tabular}{|c|r|r|}
\hline & The Yomiuri Shimbun & The New York Times \\
\hline Can Control & $31.30 \%$ & $12.37 \%$ \\
\hline Cannot Control & $0.43 \%$ & $0.38 \%$ \\
\hline Under Control & $23.04 \%$ & $9.97 \%$ \\
\hline Uncertain & $11.67 \%$ & $16.65 \%$ \\
\hline Not Applicable & $33.44 \%$ & $60.09 \%$ \\
\hline
\end{tabular}

Table 7: $\quad$ Impact of the Y2K problem.

\begin{tabular}{|c|r|r|}
\hline & The Yomiuri Shimbun & The New York Times \\
\hline Severe & $0.00 \%$ & $0.32 \%$ \\
\hline Inconvenient & $0.13 \%$ & $1.12 \%$ \\
\hline No Impact & $27.00 \%$ & $4.01 \%$ \\
\hline Uncertain & $36.67 \%$ & $23.19 \%$ \\
\hline No mention & $36.32 \%$ & $70.57 \%$ \\
\hline
\end{tabular}

\subsection{How experts dealt with the Y2K problem}

We define an "expert" as a professor who teaches at a college or university, or an individual who conducts studies in a laboratory. Experts influence the decisions of the government or the attitude of the government towards the public. Moreover, experts are highly trusted by the public. For these reasons, experts should deal with problems actively and speak out appropriately. In the case of the $\mathrm{Y} 2 \mathrm{~K}$ problem, experts did not inform the public directly. However, experts informed the public by speaking in newspapers or weekly magazines, or by publishing books on the Y2K problem.

We investigated the discipline of experts who spoke about the Y2K problem in The Asahi Shimbun and USA Today. Articles in newspapers that appeared after December 31, 1999 were not considered in this investigation. The investigation was conducted using "G-Search" in the Newspaper Library and 
"ProQuest NewsStand" in the National Diet Library. Articles in The Asahi Shimbun used in this investigation included the Tokyo morning edition and evening edition, but not local editions. The searches of The Asahi Shimbun and USA Today were conducted using the keywords "Y2K AND professor," "Y2K AND lab," and "Y2K AND university." The experts who spoke about the Y2K problem in these articles were then chosen. The results of this investigation are listed in Table 8.

Table 8 indicates that there were few engineers who spoke about the Y2K problem in Japan, although the $\mathrm{Y} 2 \mathrm{~K}$ problem was related to computers. In particular, in Japan, remarks that are understood as common sense by engineers managing computers were not reported. These remarks are as follows:

(1) Numerous troubles accompany many computers.

(2) Various systems are organized on the assumption of (1).

One of the questions of the Y2K problem was why experts did not speak out, as the expected role of experts is to actively inform the public.

Ross Anderson, an eminent cryptographer at the University of Cambridge in England, investigated many programs within the university and analyzed what would have happened if these programs had not been Y2K-compliant. Based on his analysis, he wrote a report in 1999 stating that no disruptions would have occurred in organizations with information systems similar to those at the University of Cambridge [17].

As noted previously, experts in Japan should also have taken up the Y2K problem as an object of research.

Table 8: $\quad$ Disciplines of experts appearing in newspaper articles.

\begin{tabular}{|l|l|l|l|l|l|l|}
\hline & Engineering & \multicolumn{5}{|c|}{ Social Sciences } \\
\hline Discipline & & Sociology & Economics & Law & Business & Politics \\
\hline Japan & 2 people & 5 people & 2 people & 1 person & 1 person & 1 person \\
\hline U.S. & 7 people & 3 people & 1 person & 0 & 0 & 0 \\
\hline
\end{tabular}

A Japanese expert in business administration did actively speak about the Y2K problem. He seriously considered the Y2K problem and the necessity of open-source programs that were Y2K-compliant. In addition, he made the appropriate remark, as an expert: (1)“'It is impossible to make all systems Y2Kcompliant, no matter how hard people try, as long as people are the managers of computer systems."

However, the same expert made the following inappropriate remarks, which were found by investigating Web articles: (2)"Ignore the probability of events and notice only the impact of events." This expert may be trying to say there are events that require countermeasures, even if the probability is very low. Even so, it is difficult to say that this remark is appropriate.

If we dealt with the $\mathrm{Y} 2 \mathrm{~K}$ problem with the attitude of remark (2), all problems that might have a serious impact would become cause for concern. Risks such as an accidental missile launch must be considered, because the problems in embedded computer chips were unknown. While there was a 
possibility that these types of computer and social problems could have occurred, the probability was very low. They were also not unique to the Y2K problem and should not have led to overreactions. Therefore, we suggest that this remark by experts may have led the mass media to sensationalize the $\mathrm{Y} 2 \mathrm{~K}$ problem.

In summary, when judging whether countermeasures are needed, we should compare the risk with the risks of similar problems using the probability of the event times the impact associated with the event.

\section{Suggestions for the Year 2038 problem}

There are a number of risks to the information infrastructure, including the Year 2038 problem, cyber terrorism, disasters such as earthquakes, and the risk to the information infrastructure from human error in operating machines or computers.

Methods of countermeasures against these risks are classified into risk management and crisis management. Risk management involves the countermeasures before the risk event occurs, and crisis management involves the countermeasures after the risk event occurs. Risk management is mainly conducted when the time of the occurrence of a problem is clear and the probability of occurrence is high. In contrast, crisis management is mainly conducted when the time of occurrence of the problem and the probability of occurrence are unclear. In Table 9, risk management and crisis management's different ways of categorizing are shown by classifying the risks against the information infrastructure using the countermeasures that are mainly conducted. In this section, we suggest how to deal with the Year 2038 problem, which is very similar to the $\mathrm{Y} 2 \mathrm{~K}$ problem from the viewpoint of the cause of the problem and potential impact and from the viewpoint of risk communication with the knowledge we obtained by analyzing the Y2K problem.

Table 9: Classification of risks against the information infrastructure.

\begin{tabular}{|l|l|}
\hline \multirow{2}{*}{ Risk Management } & Year 2000 problem \\
\cline { 2 - 2 } & Year 2038 problem \\
\hline \multirow{3}{*}{ Crisis Management } & Cyber Terrorism \\
\cline { 2 - 2 } & Disasters such as Earthquakes \\
\cline { 2 - 2 } & Human Error \\
\hline
\end{tabular}

\subsection{Description of the Year 2038 problem}

The Year 2038 problem may cause operating systems, some computer software, and embedded computer chips to fail before or in the Year 2038 as a result of the representation of the date in some programming languages [18].

UNIX-type operating systems and the $C$ language represent system time as the number of seconds since January 1, 1970. The time $t$ data type, a signed 32bit integer, is used to store this second count. Thus, when the time exceeds the maximum number $\left(2^{31}-1=2147483647\right.$ seconds), it is thought that the computers cannot represent the time properly. This problem is going to occur at 03:14:08 UTC (Coordinated Universal Time), January 19, 2038. Times beyond 
this moment will be represented as a negative number, because some computer systems will see these times not as January 19, 2038, but as December 14, 1901. For this reason, it is likely that some systems may fail.

We verified the kinds of problems that occur when the system time in Windows and Linux is set ahead by using a virtual machine, Vmware Workstation 5.0.0. Table 10 shows the consequences of this experiment.

Although we could not specify the cause of the inability to operate a keyboard and a mouse, we could say that this is a fatal problem. However, both problems did not happen in Windows XP. Therefore, the bug has already been fixed in Windows XP, and the bug should be fixed soon in Linux, too.

Table 10: The consequences of setting ahead the system time.

\begin{tabular}{|c|c|c|c|c|}
\hline $\mathrm{OS}$ & \multicolumn{2}{|c|}{ Linux } & \multicolumn{2}{|l|}{ Windows } \\
\hline 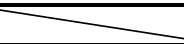 & Vine Linux & Fedora Core & & \\
\hline Version & $2.6,4.0$ & $1.0,6.0$ & $95,98, \mathrm{ME}, 2000$ & $\mathrm{XP}$ \\
\hline Consequence & $\mathrm{X}, \mathrm{T}$ & $\bar{T}$ & $\mathrm{X}$ & + \\
\hline
\end{tabular}

$\mathrm{X}$ : Not being able to operate a keyboard and a mouse

T: The system time goes back to December 14, 1901

+ : No problem happens

\subsection{Consideration of the Year 2038 problem}

The Year 2038 problem may occur in application software and embedded computer chips programmed by the $\mathrm{C}$ language, which is the most common program language. Therefore, the impact of this problem can be very broad.

The difference between the Y2K problem and the Year 2038 problem is the cause of the problem. The cause of the $\mathrm{Y} 2 \mathrm{~K}$ problem relates to application software and types of data. In contrast, the cause of the Year 2038 problem relates to a definition of the date in the $\mathrm{C}$ language.

Although the Year 2038 problem is considered to occur thirty years from now, the Year 2038 problem has already caused problems in some ATMs in January 1,2004 . The cause of this problem is that application software internally has a process that doubles the time. Therefore, the problem occurs in the middle of the time between January 1, 1970 and January 19, 2038. In addition, there are some systems, such as credit card settlement systems and reservation systems, which handle the previous time, and some problems may occur in these systems before 2038. Moreover, it takes a long time for the application software and the embedded computer chips to be fixed. Thus, the bug should be fixed in the early step.

\subsection{How should we deal with the Year 2038 problem}

We investigated the $\mathrm{Y} 2 \mathrm{~K}$ problem and analyzed it from the viewpoint of risk communication. With this knowledge, we next describe how participants should conduct risk communication to counter the Year 2038 problem. 
(1) There are a few things that the public can do at present time regarding the Year 2038 problem, if they know the risk. Therefore, although the government and mass media need not inform the public of this risk at present, we suggest they inform the public several years before 2038, as was done for the Y2K problem.

(2) What is needed at the present time is risk communication between the government, experts, and the corporate sector. For example, the government should encourage experts and businesses to change definitions in the $\mathrm{C}$ language so that systems and computers are able to handle dates after 2038 .

(3) The government and experts should direct developers of embedded computer chips to be able to identify parts that use date information in internal systems. It will help critical infrastructures be able to check the systems smoothly in the future. Experts, especially engineers, should actively deal with the problem in the manner of Ross Anderson, the cryptographer at the University of Cambridge, and should assume their appropriate role by actively speaking out.

(4) Mass media should inform the public correctly and voluminously of the risk several years before 2038. Japanese weekly magazine informed the public sensationally after the government made the safety announcement in the $\mathrm{Y} 2 \mathrm{~K}$ problem. This coverage was not appropriate.

(5) Finally, the comparison of one risk with other risks based on the probability of an event times the impact associated with the event and judging whether countermeasures are necessary is important. This idea should also be adopted to consider whether or not to take countermeasures against the problems in other critical infrastructures.

\section{Conclusion}

We investigated and analyzed the $\mathrm{Y} 2 \mathrm{~K}$ problem from the viewpoint of risk communication and suggested methods by which participants should deal with the Year 2038 problem.

The Y2K problem was dealt with appropriately because the prediction of the occurrence of events and countermeasures was relatively accurate. Therefore, it is also likely that the Year 2038 problem will be handled appropriately.

In contrast, since we do not know when and how cyber terrorism or disasters such as earthquakes will occur, it is also necessary at the present time to seriously consider how to deal with these problems and conduct risk communication.

\section{References}

[1] Prime Minister of Japan and His Cabinet, "2000 Year Problem”, http://www.kantei.go.jp/jp/pc2000/houkokusyo/honbun.html

[2] TIME, "The History and the Hype", http://www.time.com/ time/teach/glenfall99/y2k.pdf

[3] "Defining Risk", http://www.ilankelman.org/abstracts/kelman2003frn.pdf 
[4] National Research Council, "Improving Risk Communication", National Academy Press, Washington DC (1989)

[5] Mariko Nakamura, "Communication model for risk information sharing", Proceedings of the Human Interface Symposium (2004)

[6] Ministry of the Environment, "The report of investigation for the case on risk communication 2000", http:/www.env.go.jp/chemi/communication/ h12jirei/index.html

[7] Ryoichi Sasaki, 'Developments Design on 'Multiplex Risk Communicator' and Its Trial Application", Information Processing Society of Japan Journal, Vol46, No8, pp2120-2128, 200508

[8] The Newspaper Library, http://www.pressnet.or.jp/library/english/ index.html

[9] ProQuest Newsstand, http://www.proquest.com/products_pq/descriptions/ newsstand.shtml

[10] Internet Archive, http://www.archive.org/index.php

[11] The Society for Risk Analysis: Japan-Section, "HANDBOOK of Risk Research", p265, TBS Britannica, Tokyo (2000)

[12] The White House, "The Federal Government is Y2K Ready", http://clinton4.nara.gov/WH/Work/121499_1.html

[13] Japan Audit Bureau of Circulations, "Report of Penetration Rate of Newspapers, 2006, July-Dec.”, http://adv.yomiuri.co.jp/yomiuri/xls/ busu00.xls

[14] NewsPaper Association of America, “Top 100 Newspapers/Newspaper Combinations", http://www.newspapermedia.com/docs/Top100.pdf

[15] US Census Bureau, “America's Families and Living Arrangements: 2006, http://www.census.gov/population/socdemo/hh-fam/cps2006/ tabH1-all.xls

[16] Akiko Fukumoto and Mary M. Meares, "Y2K and the Construction of Risk Perception in Newspapers in Japan and the United States", http://www.mediacom.keio.ac.jp/publication/pdf2005/review27/fukumoto. pdf

[17] Ross Anderson, "The Millennium Bug-Reasons not to Panic", http://www.ftp.cl.cam.ac.uk/ftp/users/rja14/y2k.pdf

[18] The Project 2038 Frequently Asked Questions, http://maul.deepsky.com/ \%7Emerovech/ 2038.html 